\title{
Praktikalitas Media Video Tutorial sebagai Suplemen Digital Learning pada Mata Kuliah Persamaan Diferensial Biasa
}

\author{
Ronal Rifandi $^{1)}$, Defri Ahmad ${ }^{1)}$, Meria Ultra Gusteti ${ }^{2)}$ \\ ${ }^{1)}$ Universitas Negeri Padang \\ ${ }^{2}$ STKIP Adzkia Padang \\ r.rifandi@fmipa.unp.ac.id
}

\begin{abstract}
Industrial revolution 4.0 in which digital technology being more integrated in all aspects of human life will demand the new reform of education world. Not only can it affect the curriculum being taught, but it will also lead to the changes of the methods and approaches in conducting the lesson. One of the changes is the use of digital learning. Universitas Negeri Padang has regulation of conducting lesson through e-learning platform proportionally for all courses, including the course of Ordinary Differential Equation. Ordinary Differential Equation is a mandatory course that should be taken by mathematics department's students. In order to support students to develop their under standing about the concept and its application while using digital learning method, the researchers develop some tutorial video as supplementary media. Therefore, this study aimed to describe the practicality of the tutorial video. This is a descriptive research where the data were collected using closed questionnaire. The respondents were 39 mathematics students of Universitas Negeri Padang who joined Ordinary Differential Equation Course in the semester of January-June 2020. The result indicates that the video tutorials used in the course are in the category of very practice with the score percentage $86,6 \%$.
\end{abstract}

Keywords : Video tutorial, Ordinary differential equation, Digital learning

his is an open access article distributed under the Creative Commons 4.0 Attribution License, which permits unrestricted use, distribution, and reproduction in any medium, provided the original work is properly cited. $\odot 2018$ by author and Universitas Negeri Padang.

\section{PENDAHULUAN}

Revolusi Industri 4.0 merupakan sebuah tantangan yang dihadapi oleh dunia saat ini, termasuk Indonesia. Dalam revolusi ini salah satu cirinya adalah adanya perpaduan teknologi yang mengaburkan batas antara bidang fisik, digital, dan biologis (Klaus, 2016). Selain itu, perkembangan yang pesat pada teknologi kecer dasan buatan (artificial intelegence) juga meru pakan karakteristik utama dari revolusi tersebut (Shahroom \& Hussin, 2018).

Integrasi teknologi tersebut memberikan pengaruh yang signifikan terhadap aspek-aspek kehidupan (Ghufron, 2018). Berkaitan dengan hal itu, dunia pendidikan memiliki peran penting untuk mempersiapkan sumber daya manusia yang unggul untuk mampu menghadapi tan tangan hidup dalam masa revolusi industri 4.0 tersebut (Huseno, 2018; Thamrin \& Kadarudin, 2019). Termasuk di dalamnya pengembangan kemampuan literasi dan juga keterampilan berpi kir tingkat tinggi (Rahmi \& Alberida, 2017; Rifandi, Puspita, \& Mulyati, 2019).

Inovasi dalam dunia pendidikan, terutama pada sektor pendidikan tinggi, sebagai efek dari adanya revolusi 4.0 nampak jelas dengan beru bahnya metode dan pendekatan pembelajaran konvensional yang selama ini sudah ada menjadi pembelajaran dengan formula baru yang lebih menitikberatkan pada keterbukaan akses infor masi dan pemanfaatan teknologi (Gleason, 2018; Huseno, 2018). Selain itu ahli lainnya mengatakan bahwa dunia digital semakin masuk mempengaruhi dunia pendidikan dan keteram pilan melalui cara-cara inovatif dalam melaku kan proses pendidikan, transfer pengetahuan maupun pelatihan keterampilan (Grand Clement, 2017). Hal ini juga sejalan dengan adanya inte grasi Science, Technology, Engineering dan Mathematics (STEM) dalam pembelajaran yang bertujuan untuk menyiapkan peserta didik dalam menyongsong persaingan dunia global (Widya, Rifandi, \& Rahmi, 2019).

Selanjutnya, banyak istilah untuk mendefi nisikan beberapa inovasi dalam metode pembela jaran yang sejalan dengan perkembangan revo lusi keempat ini. Salah satu diantaranya adalah istilah digital learning atau sering juga dikenal dengan nama electronic learning (e-learning). Menurut American Society of Training and Education (ASTD) digital learning didefinisikan sebagai sebuah pembelajaran yang mengintegra 
sikan media digital dalam prosesnya, media digital ini antara lain: internet, komputer, siaran satelit, rekaman audio, rekaman video, tv inter aktif, dan compact disks (Lin, Chen, \& Liu, 2017). Pendapat lainnya mengatakan bahwa digital learning yaitu seperangkat metode yang dimediasi oleh teknologi untuk diterapkan dalam mendukung proses pembelajaran dan dapat mencakup unsur-unsur penilaian, bimbingan belajar, dan pengajaran (Wheeler, 2012).

Universitas Negeri Padang (UNP) sebagai salah satu perguruan tinggi yang berkomitmen dalam menyiapkan lulusan yang mampu menye suaikan diri dengan perkembangan zaman juga membuat kebijakan terkait pelaksanaan digital learning dalam perkuliahan (Peraturan Rektor UNP No. 08 Tahun 2018). Setiap dosen pengam pu mata kuliah diharuskan melakukan perku liahan yang salah satu variasinya adalah melalui sistem pembelajaran melalui platform e-learning (digital learning). Hal ini juga berlaku untuk mata kuliah Persamaan Diferensial Biasa (PDB). Penggunaan e-learning dalam pembelajaran saat penelitian ini berlangsung juga diperkuat dengan kondisi pandemi global penyebaran wabah covid-19 yang mengharuskan adanya pemba tasan sosial agar penyebarannya dapat dimini malisir (SE Rektor UNP No. 1593/UN35/AK/ 2020).

Mata kuliah PDB, yang merupakan mata kuliah wajib di Jurusan Matematika, memiliki sinopsis sebagai berikut 1) Pembahasan menge nai pengertian, solusi, orde dan pangkat dari PDB, 2) Menyelesaikan PDB orde 1, 2 dan tinggi, 3) Menyelesaikan sistem PDB orde 1, 4) Menentukan solusi deret dari PDB, dan 5) Transformasi Laplace (Buku Kurikulum Prodi S1 Pendidikan Matematika dan S1 Matematika UNP, 2019). Setiap mahasiswa yang mengambil mata kuliah ini diharapkan memiliki pema haman yang komprehensif serta mampu meng gunakan konsep-konsep yang telah dipelajari dalam menyelesaikan permasalahan sehari-hari yang berkaitan dengan konsep persamaan dife rensial biasa.

Sehubungan dengan hal tersebut, dosen pengampu mata kuliah PDB dituntut agar lebih kreatif dalam menyiapkan bahan perkuliahan, tidak hanya untuk dipakai dalam perkulihan tatap muka, namun juga pengintegrasiannya dalam digital learning. Berdasarkan penjelasan di atas maka dikembangkan media pembelajaran dalam bentuk video tutorial sebagai suplemen dalam digital learning pada mata kuliah PDB.
Banyak definisi mengenai video tutorial salah satunya adalah yang menyatakan bahwa video tutorial merupakan panduan tentang cara menjelaskan sesuatu, baik materi pembelajaran atau pelatihan yang disajikan dalam bentuk media dengan tujuan membuat suatu penjelasan atas materi menjadi lebih mudah (Sumantri, 2019). Sedangkan suplemen pembelajaran meru pakan media tambahan yang dimanfaatkan untuk melengkapi pembelajaran, berguna untuk mencapai tujuan yang sebelumnya belum terca pai dengan perangkat yang telah tersedia (Winar to \& Yunianta, 2018).

Pengembangan sebuah media pembela jaran tentu harus sesuai dengan tahap-tahap pengembangan yang dipakai oleh peneliti dalam proses pengembangannya. Hal ini perlu untuk dilakukan agar media yang dihasilkan valid, praktis dan efektif untuk digunakan dalam pembelajaran (Koumi, 2006). Namun sebagai fokus pada artikel ini rumusan masalahnya adalah bagaimana praktikalitas media video tutorial sebagai suplemen digital learning pada mata kuliah PDB.

\section{METODE PENELITIAN}

Penelitian ini adalah penelitian deskriptif yang bertujuan untuk mendeskripsikan prak tikalitas media video tutorial yang dikembang kan sebagai suplemen digital learning pada mata kuliah PDB. Sebagai instrumen penelitian, digunakan kuisioner berupa angket tertutup. Dalam Kamus Besar Bahasa Indonesia kuisioner adalah "alat riset atau survei yang terdiri atas serangkaian pertanyaan tertulis, bertujuan men dapatkan tanggapan dari kelompok orang terpi lih melalui wawancara pribadi atau melalui pos"(KBBI) Online," n.d.) Selanjutnya, angket tertutup yaitu angket yang berisi pernyataanpernyataan disertai dengan jawaban yang telah disediakan.

Pada penelitian ini kuisioner yang diguna kan adalah angket praktikalitas yang dikem bangkan oleh Lestari, dkk (2018) yang telah dimodifikasi sesuai kebutuhan. Komponen prak tikalitas yang diteliti berkaitan dengan aspek kemudahan penggunaan, efektivitas waktu pem belajaran, daya tarik dan kebermanfaatan dari media video tutorial yang dikembangkan. Di dalam angket tersebut digunakan skala likert yang sudah disesuaikan sebagaimana dapat dilihat pada Tabel 1. 
Tabel 1. Kriteria Penilaian Hasil

Pengukuran Angket Praktikalitas

\begin{tabular}{|c|c|}
\hline Skor & Keterangan \\
\hline 1 & Sangat Tidak Setuju \\
\hline 2 & Tidak Setuju \\
\hline 3 & Setuju \\
\hline 4 & Sangat Setuju \\
\hline
\end{tabular}

Media video tutorial yang diuji prak tikalitasnya adalah video tutorial yang berisi materi singkat dilengkapi dengan contoh soal dan pemberian latihan. Video ini dibuat dengan menggunakan media powerpoint yang kemudian dijelaskan dengan slideshow di layar komputer disertai penjelasan lisan. Penyajian ini direkam dengan software perekam layar komputer berna ma Bandicam. Setelah selesai direkam, video kemudian diunggah ke media youtube dan dibagikan ke situs www.elearning2.unp.ac.id untuk dibahas dalam pembelajaran online bersama mahasiswa.

Topik yang dibahas dalam video yang diuji praktikalitasnya adalah metode variasi para meter, persamaan Cauchy-Euler, solusi deret pangkat dan metode Frobenius. Video tutorial yang telah diunggah dapat dilihat melalui link url berikut.

https://www.youtube.com/watch?v=kqt9b404hn 4\&list=PLEl0AUJuyZjEksooE8xp5aC43QBj4E oKE.

Responden pada penelitian ini yaitu 39 orang mahasiswa Jurusan Matematika UNP yang mengambil mata kuliah PDB pada semes ter Januari-Juni 2020. Data respon mahasiswa dari kuisioner yang diberikan diolah mengguna kan rumus berikut.

$$
\mathrm{p}=\frac{\sum \text { Skor per item }}{\text { Skor Maksimal }} \times 100 \%
$$

Hasil persentase yang diperoleh diinter pretasikan dengan kategori sebagaimana terda pat pada Tabel 2.

Tabel. 2 Kriteria Praktikalitas Video

\begin{tabular}{|c|c|}
\hline$\%$ & Kategori \\
\hline $85<\mathrm{P} \leq 100$ & Sangat Praktis \\
\hline $75<\mathrm{P} \leq 85$ & Praktis \\
\hline $59<\mathrm{P} \leq 75$ & Cukup Praktis \\
\hline $54<\mathrm{P} \leq 59$ & Kurang Praktis \\
\hline$\leq 54$ & Kurang Praktis Sekali \\
\hline
\end{tabular}

Dimodifikasi dari Purwanto (2011)

\section{HASIL DAN PEMBAHASAN}

\section{Hasil Penelitian}

Secara umum data hasil angket prak tikalitas media video tutorial mata kuliah PDB ini dapat dilihat pada Tabel 3 berikut.

Tabel 3. Rekapitulasi Hasil Uji Praktikalitas

\begin{tabular}{|c|c|c|c|c|}
\hline Aspek & Skor & maks & $\%$ & Kategori \\
\hline $\begin{array}{c}\text { Kemudahan } \\
\text { penggunaan }\end{array}$ & 1089 & 1248 & 87,3 & $\begin{array}{c}\text { Sangat } \\
\text { Praktis }\end{array}$ \\
\hline $\begin{array}{c}\text { Efektivitas } \\
\text { waktu pem } \\
\text { belajaran }\end{array}$ & 410 & 468 & 87,6 & $\begin{array}{c}\text { Sangat } \\
\text { Praktis }\end{array}$ \\
\hline Daya tarik & 249 & 312 & 79,8 & Praktis \\
\hline Kemanfaatan & 684 & 780 & 87,7 & $\begin{array}{c}\text { Sangat } \\
\text { Praktis }\end{array}$ \\
\hline Jumlah & 2432 & 2808 & 86,6 & $\begin{array}{c}\text { Sangat } \\
\text { Praktis }\end{array}$ \\
\hline
\end{tabular}

Berdasarkan Tabel 3 dapat disimpulkan bahwa media video tutorial yang diuji memiliki kategori praktikalitas sangat praktis. Untuk lebih detilnya, data hasil angket untuk setiap aspek disajikan sebagai berikut.

\section{Aspek kemudahan penggunaan}

Hasil angket mahasiswa pada aspek ini dapat dilihat pada Tabel 4.

Tabel 4. Aspek Kemudahan Penggunaan

\begin{tabular}{|c|c|c|c|}
\hline Aspek & Skor & $\%$ & Kategori \\
\hline $\begin{array}{l}\text { Materi yang disajikan } \\
\text { jelas }\end{array}$ & 143 & 91,7 & $\begin{array}{l}\text { Sangat } \\
\text { Praktis }\end{array}$ \\
\hline $\begin{array}{l}\text { Materi yang disajikan } \\
\text { sederhana }\end{array}$ & 136 & 87,2 & $\begin{array}{l}\text { Sangat } \\
\text { Praktis }\end{array}$ \\
\hline $\begin{array}{l}\text { Suara yang dihasilkan } \\
\text { jelas }\end{array}$ & 129 & 82,7 & Praktis \\
\hline $\begin{array}{l}\text { Bahasa yang } \\
\text { digunakan mudah } \\
\text { dipahami }\end{array}$ & 144 & 92,3 & $\begin{array}{l}\text { Sangat } \\
\text { Praktis }\end{array}$ \\
\hline $\begin{array}{l}\text { Ukuran tulisan jelas } \\
\text { dan mudah dibaca }\end{array}$ & 140 & 89,7 & $\begin{array}{l}\text { Sangat } \\
\text { Praktis }\end{array}$ \\
\hline $\begin{array}{l}\text { Isi secara keseluruhan } \\
\text { mudah dipahami }\end{array}$ & 136 & 87,2 & $\begin{array}{l}\text { Sangat } \\
\text { Praktis }\end{array}$ \\
\hline $\begin{array}{l}\text { Ukuran file video } \\
\text { mudah untuk } \\
\text { didownload }\end{array}$ & 127 & 81,4 & Praktis \\
\hline $\begin{array}{l}\text { Durasi video sudah pas } \\
\text { dan memadai }\end{array}$ & 134 & 85,9 & Praktis \\
\hline Jumlah & 1089 & 87,3 & $\begin{array}{l}\text { Sangat } \\
\text { Praktis }\end{array}$ \\
\hline
\end{tabular}

Berdasarkan data pada Tabel 4. Enam dari delapan butir pernyataan dalam aspek ini memiliki kategori sangat praktis. Persentase 
skor paling tinggi ada pada butir pernyataan Bahasa yang digunakan mudah dipahami yaitu sebesar 92,3\%. Persentase skor yang tinggi juga terdapat pada pernyataan Materi yang disajikan dalam video tutorial yang diuji jelas yaitu $91,7 \%$. Hal ini menunjukkan bahwa mayoritas responden sangat setuju dengan kedua pernya taan tersebut. Selanjutnya, pada aspek kemu dahan penggunaan ini, persentase skor terendah ada pada pernyataan ukuran video mudah untuk di download yaitu sekitar $81,4 \%$. Namun secara umum persentase skor untuk aspek kemudahan penggunaan ini adalah 87,3\% dan berada pada kategori sangat praktis.

2. Aspek efektivitas waktu pembelajaran

Hasil rekapitulasi angket tentang aspek efektivitas waktu pembelajaran dengan menggu nakan video tutorial dapat dilihat pada Tabel 5.

Tabel 5. Aspek Efektivitas Waktu Pembelajaran

\begin{tabular}{|l|c|c|c|}
\hline \multicolumn{1}{|c|}{ Aspek } & Skor & \% & Kategori \\
\hline $\begin{array}{l}\text { Dengan video tutorial } \\
\text { yang disajikan, } \\
\text { pembelajaran terkait } \\
\text { topik yang dibahas } \\
\text { menjadi lebih efektif }\end{array}$ & 138 & 88,5 & $\begin{array}{l}\text { Sangat } \\
\text { Praktis }\end{array}$ \\
\hline $\begin{array}{l}\text { Dengan video tutorial } \\
\text { yang disajikan, } \\
\text { pembelajaran terkait } \\
\text { topik yang dibahas } \\
\text { menjadi efisien }\end{array}$ & 135 & 86,5 & $\begin{array}{l}\text { Sangat } \\
\text { Praktis }\end{array}$ \\
\hline $\begin{array}{l}\text { Mahasiswa dapat } \\
\text { belajar sesuai dengan } \\
\text { kemampuan belajarnya }\end{array}$ & 137 & 87,8 & $\begin{array}{l}\text { Sangat } \\
\text { Praktis }\end{array}$ \\
\hline \multicolumn{1}{|c|}{ Jumlah } & 410 & 87,6 & $\begin{array}{l}\text { Sangat } \\
\text { Praktis }\end{array}$ \\
\hline
\end{tabular}

Berdasarkan data pada Tabel 5 terlihat bahwa mayoritas responden setuju bahwa melalui media video tutorial ini pembelajaran menjadi efektif dan efisien dengan persentase skor $86-88,5 \%$ untuk setiap butir pada aspek ini.

\section{a. Aspek daya tarik}

Hasil angket mahasiswa pada aspek daya tarik dapat dilihat pada Tabel 6. Dari Tabel 6 dapat ditarik kesimpulan jika dibandingkan dengan aspek-aspek praktikalitas lainnya yang diuji, aspek daya tarik ini memiliki persentase skor yang paling rendah yaitu $79,8 \%$. Hal ini menyebabkan aspek ini menjadi satu-satunya aspek yang berada dalam kategori praktis.
Tabel 6. Aspek Daya Tarik

\begin{tabular}{|c|c|c|c|}
\hline Aspek & Skor & $\%$ & Kategori \\
\hline $\begin{array}{c}\text { Tampilan video } \\
\text { tutorial menarik }\end{array}$ & 118 & 75,6 & Praktis \\
\hline $\begin{array}{c}\text { Ketertarikan } \\
\text { terhadap video } \\
\text { tutorial tinggi }\end{array}$ & 131 & 84,0 & Praktis \\
\hline Jumlah & 249 & 79,8 & Praktis \\
\hline
\end{tabular}

\section{b. Aspek kemanfaatan}

Hasil rekapitulasi angket tentang aspek kemanfaatan dalam menggunakan video tutorial dapat dilihat pada Tabel 7.

Tabel 7. Aspek Kemanfaatan

\begin{tabular}{|l|c|c|c|}
\hline \multicolumn{1}{|c|}{ Aspek } & Skor & $\%$ & Kategori \\
\hline $\begin{array}{l}\text { Video tutorial } \\
\text { membantu pemahaman } \\
\text { konsep }\end{array}$ & 134 & 85,9 & $\begin{array}{l}\text { Sangat } \\
\text { Praktis }\end{array}$ \\
\hline $\begin{array}{l}\text { Contoh soal membantu } \\
\text { dalam memahami } \\
\text { materi }\end{array}$ & 148 & 94,9 & $\begin{array}{l}\text { Sangat } \\
\text { Praktis }\end{array}$ \\
\hline $\begin{array}{l}\text { Video tutorial } \\
\text { membantu Anda untuk } \\
\text { belajar mandiri }\end{array}$ & 144 & 92,3 & $\begin{array}{l}\text { Sangat } \\
\text { Praktis }\end{array}$ \\
\hline $\begin{array}{l}\text { Video tutorial } \\
\text { membantu Anda untuk } \\
\text { belajar berkelompok }\end{array}$ & 124 & 79,5 & Praktis \\
\hline $\begin{array}{l}\text { Video tutorial } \\
\text { meningkatkan minat } \\
\text { belajar }\end{array}$ & 134 & 85,9 & $\begin{array}{l}\text { Sangat } \\
\text { Praktis }\end{array}$ \\
\hline \multicolumn{1}{|c|}{ Jumlah } & 684 & 87,7 & $\begin{array}{l}\text { Sangat } \\
\text { Praktis }\end{array}$ \\
\hline
\end{tabular}

Secara umum, persentase skor praktikali tas untuk aspek kemanfaatan ini paling tinggi dibandingkan dengan aspek yang lain yaitu $87,7 \%$. Salah satu butir pernyataan pada aspek ini menjadi butir yang memperoleh persentase skor paling tinggi di antara keseluruhan butir pernyataan pada angket praktikalitas ini. Butir pernyataan itu adalah pernyataan bahwa contoh soal yang disajikan dalam media video tutorial ini membantu mereka dalam memahami materi, yaitu dengan persentase skor 94,9\%. Selain itu mayoritas responden juga setuju bahwa video tutorial ini membantu mereka dalam belajar secara mandiri (dengan persentase skor 92,3\%). Sebaliknya, persentase skor untuk butir pernya taan tentang dukungan video tutorial ini terha dap responden dalam belajar kelompok memiliki persentase paling rendah pada aspek ini yaitu $79,5 \%$. 


\section{Pembahasan}

Pada bagian ini akan dipaparkan pemba hasan dari setiap aspek dengan data angket praktikalitasnya telah disajikan dibagian hasil di atas. Untuk aspek kemudahan penggunaan, media video tutorial yang dikembangkan oleh peniliti memperhatikan kriteria agar media ini praktis dan mudah untuk digunakan. Materi di dalam video tutorial disajikan langsung kepada pokok materi yang ingin dijelaskan. Tidak diser tai dengan penjelasan pengantar yang panjang dan berbelit. Sehingga memudahkan mahasiswa dalam mendapatkan materi yang jelas, seder hana dan terfokus. Hal ini sejalan dengan karakteristik video tutorial untuk pembelajaran sebagaimana yang dikemukakan oleh para ahli (Busyaeri, Udin, \& Zaenuddin, 2016; Riyana, 2007).

Selain itu, aspek bahasa yang dipakai juga jelas dan sederhana baik dalam bahasa lisan maupun tulisan. Untuk bahasa lisan, digunakan bahasa yang seolah-olah berbentuk dialog dua arah dengan audien sehingga mahasiswa yang menonton video merasa terlibat dalam pembela jaran layaknya komunikasi dalam pembelajaran tatap muka. Hal ini ditunjang dengan komuni kasi aktif dalam kolom komentar dan platform aplikasi chatting jika mahasiswa memiliki perta nyaan terkait materi yang disajikan. Sedangkan untuk contoh penggunaan tulisan dalam video tutorial ini dapat dilihat pada Gambar 1. Bahasa lisan dan tulisan yang jelas dan tidak berbelitbelit akan membuat media menjadi praktis untuk digunakan (Nurseto, 2012).

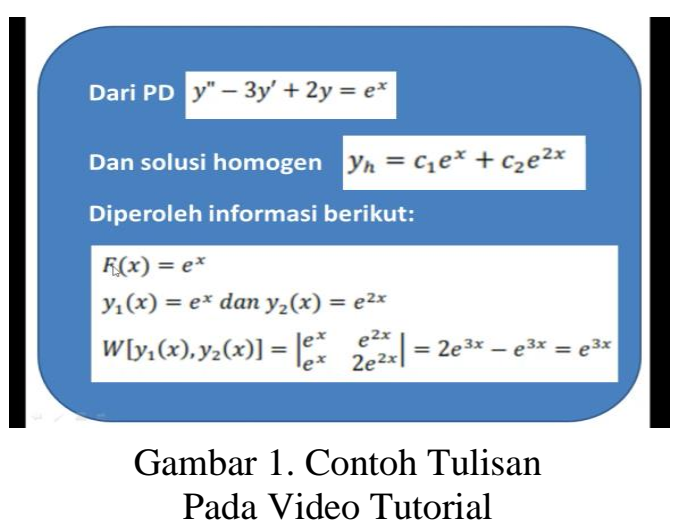

Untuk durasi video yang diunggah online berkisar antara 15-22 menit. Hal ini dengan pertimbangan agar mahasiswa mudah dalam mengakses maupun mengunduhnya. Data dari hasil angket yang menunjukkan butir pernyataan bahwa ukuran video mudah untuk diunduh memiliki persentase skor paling rendah diaspek kemudahan penggunaan ini (yaitu 81,4\%). Setelah ditelusuri, hal ini terjadi dikarenakan mahasiswa terkendala dalam akses jaringan internet sebab mereka mengakses video tutorial ini di daerah yang sebagian kondisi jaringan internetnya tidak stabil. Sedangkan untuk maha siswa yang mengakses dari lingkungan perko taan, tidak terdapat kendala.

Selanjutnya untuk aspek efektivitas waktu pembelajaran, terlihat dari data pada Tabel 5 bahwa mahasiswa setuju media video tutorial ini membantu mereka untuk menggunakan waktu belajar dengan efektif dan efisien. Selain itu media video ini juga memberikan peluang bagi mahasiswa untuk menyesuaikan kemampuan belajarnnya dengan kelanjutan materi yang sedang dipelajari. Melalui media video ini, mahasiswa dapat menggunakan waktu yang lebih fleksibel baik untuk memperdalam bagian yang lebih sulit maupun memperhatikan lebih detil langkah-langkah penggunaan konsep dalam penyelesaian soal matematika terkait.

Pada aspek daya tarik, sebagaimana data yang disajikan pada Tabel 7 , terlihat sedikit kontradiksi diantara dua butir pernyataan yang ada. Untuk pernyataan pertama yaitu video tutorial menarik persentase skornya adalah $75,6 \%$ yang merupakan persentase paling rendah dibandingkan dengan butir pernyataan lainnya. Sedangkan butir pernyataan kedua yaitu ketertarikan terhadap video tutorial tinggi dengan persentase skor $84 \%$. Setelah dianalisa, disimpulkan bahwa pernyataan pertama yang berkaitan dengan tampilan dari video tutorial yang disajikan baik dari segi visual maupun audio masih belum sepenuhnya menarik. Hal ini dikarenakan belum adanya editing tingkat lanjut yang dilakukan terhadap video yang direkam. Video yang disertai dengan tambahan musik instrumen pembuka, penutup maupun musik latar mampu menambah ketertarikan penonton. Adanya penambahan musik dalam media video dikatakan dapat menambah perhatian dari penonton terhadap sajian pembelajaran yang diberikan (Nurseto, 2012).

Sedangkan persentase skor untuk keter tarikan terhadap video tergolong tinggi, menurut analisa yang dilakukan, hal ini dikarenakan saat penelitian ini dilakukan metode pembelajaran yang diterapkan oleh institusi pendidikan di Indonesia termasuk UNP adalah pembelajaran online dalam rangka usaha pencegahan penye baran wabah covid-19 (SE Rektor UNP No. 1593/UN35/AK/2020). Dikarenakan pembela 
jaran online tersebut, untuk mata kuliah PDB mahasiswa lebih tertarik untuk menonton penje lasan melalui media audio visual dari pada mem baca buku teks saja.

Aspek berikutnya yang diuji praktikalitas nya pada penelian ini yaitu aspek kemanfaatan. Sebagaimana data pada Tabel 7 , media video tutorial dapat bermanfaat dalam membantu mahasiswa untuk memahami konsep materi, belajar mandiri dan berkelompok, serta mening katkan minat belajar mahasiswa terkait topik yang sedang dipelajari. Butir pernyataan tentang adanya contoh soal dapat membantu mahasiswa memahami materi yang memiliki persentase skor paling tinggi yaitu 94,9\% menunjukkan bahwa mahasiswa mendapatkan dukungan untuk memahami konsep melalui penggunaannya dalam contoh soal yang diberikan. Selain itu, video tutorial ini membantu mahasiswa untuk belajar secara mandiri karena sudah dibuat secara ringkas namun lengkap. Gambar 2 berikut ini menyajikan tangkapan layar video untuk contoh soal.
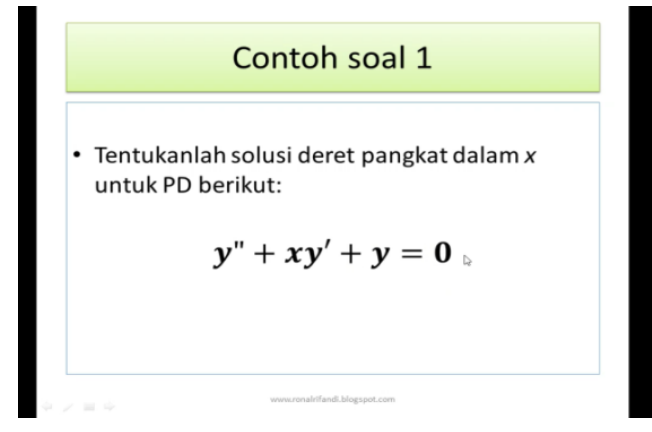

Gambar 2. Tangkapan Layar Video Untuk Contoh Soal

Selain contoh soal, mahasiswa juga diberikan latihan di akhir video untuk dikerjakan dan kemudian dikumpulkan secara online ke situs elearning. Gambar 3 berikut merupakan tangkapan layar video untuk contoh latihan.

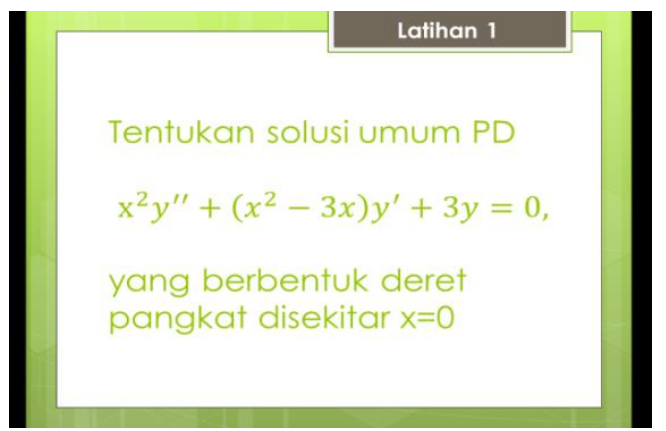

Gambar 3. Tangkapan Layar Video Untuk Latihan Soal
Hal ini sejalan dengan pendapat Pramudito (2013) tentang kelebihan media video tutorial yaitu dapat dengan mudah mengulang kembali bagian yang dianggap belum jelasoleh peserta didik sehingga menunjang dalm proses belajar secara mandiri.

\section{KESIMPULAN}

Berdasarkan hasil dan pembahasan pene litian ini dapat ditarik kesimpulan bahwa media video tutorial yang diuji praktikalitasnya memi liki persentase skor praktikalitas $86,6 \%$ dan berada pada kategori sangat praktis. Aspek prak tikalitas yang diujikan antara lain aspek kemu dahan penggunaan, efektivitas waktu pembela jaran, daya tarik dan kebermanfaatan.

Hasil tersebut mengindikasikan bahwa media video tutorial dapat digunakan sebagai sumber belajar tambahan dalam mendukung mahasiswa untuk mencapai tujuan pembelajaran pada mata kuliah Persamaan Diferensial Biasa terutama saat pembelajaran berlangsung dengan metode online atau digital learning.

\section{DAFTAR PUSTAKA}

Kamus Besar Bahasa Indonesia (KBBI) Online. (n.d.). Retrieved April 26, 2020 https://kb bi.web.id/kuesioner

Busyaeri, A., Udin, T., \& Zaenuddin, A. (2016). Pengaruh Penggunaan Video Pembelajaran Terhadap Peningkatan Hasil Belajar Mapel IPA di MIN Kroya Cirebon. Al Ibtida, Vol. 3.

Ghufron, M. A. (2018). Revolusi Industri 4.0: Tantangan, Peluang dan Solusi Bagi Dunia Pendidikan. Seminar Nasional Dan Dis kusi Panel Multidisiplin Hasil Penelitian Dan Pengabdian Kepada Masya rakat.

Gleason, N. W. (Ed.). (2018). Higher Educa tion in the Era of the Fourth Industrial Revolution. Singapore: Palgrave Mac millan. https://doi.org/10.1007/978-98113-0194-0

Grand-Clement, S. (2017). Digital Learning: Education and Skills in The Digital Age. Cambridge. Retrieved from www.rand europe.org

Huseno, T. (2018). Strategi Perguruan Tinggi dalam Upaya Meningkatkan Kualitas Sumberdaya Manusia Menghadapi Era Revolusi Industri 4.0. REKAMAN.

Klaus, S. (2016). The Fourth Industrial Revo 
lution: what it means and how to respond | World Economic Forum. Retrieved April 26, 2020, from https://www.weforum.org/ agenda/2016/01/the-fourth-industrial-revo lution-what-it-means-and-how-to-respond/

Koumi, J. (2006). Designing video and multi media for open and flexible learning. Designing Video and Multimedia for Open and Flexible Learning. https://doi.org/10. 4324/9780203966280

Kurikulum Program Studi Matematika S1 UNP. (2019). Padang: UNP.

Kurikulum Program Studi Pendidikan Mate matika S1 UNP. (2019). Padang: UNP.

Lestari, L., Alberida, H., \& Rahmi, Y. L. (2018). Validitas dan Praktikalitas Lembar Kerja Peserta Didik ( LKPD ) Materi Kingdom Plantae Berbasis Pendekatan Saintifik untuk Peserta Didik Kelas X SMA/MA. Jurnal Eksakta Pendidikan, 2 (November).

Lin, M.-H., Chen, H.-C., \& Liu, K.-S. (2017). A Study of the Effects of Digital Learning on Learning Motivation and Learning Out come. OPEN ACCESS EURASIA Journal of Mathematics Science and Technology Education, 13(7), 3553-3564. https://doi. org/10.12973/eurasia.2017.00744a

Nurseto, T. (2012). Membuat Media Pembela jaran yang Menarik. Jurnal Ekonomi Dan Pendidikan, 8(1). https://doi.org/10.21831/ jep.v8i1.706

Peraturan Rektor No. 08 Tahun 2018 tentang Pelaksanaan Perkuliahan Melalui ELearning di Universitas Negeri Padang. (2018). Padang: UNP.

Pramudito, A. (2013). Pengembangan Media Pembelajaran Video Tutorial Pada Mata Pelajaran Kompetensi Kejuruan Standar Kompetensi Melakukan Pekerjaan Dengan Mesin Bubut di SMK Muhammadiyah 1 Playen. Jurnal Pendidikan Teknik Mesin, $1-12$.

Purwanto. (2011). Evaluasi Hasil Belajar (3rd ed.). Jakarta: Pustaka Pelajar.

Rahmi, Y. L., \& Alberida, H. (2017). Improving Students' Higher Order Thinking Skills through Portfolio Assessment on Biology Curriculum and Text book Analysis Cour se. Bioeducation Journal, 1 (1), 22-33.
Rifandi, R., Puspita, V., \& Mulyati, A. (2019). The Validity of Problem Solving Based Teaching Material on Mathematical Literacy in Theme Integrated Learning. Journal of Physics: Conference Series (Vol. 1317). Institute of Physics Publishing. https://doi.org/10.1088/17426596/1317/1/012124

Riyana, C. (2007). Pedoman Pengembangan Media Video. Jakarta: P3AI UPI.

Shahroom, A. A., \& Hussin, N. (2018). Indus trial Revolution 4.0 and Education. Interna tional Journal of Academic Research in Business and Social Sciences, 8(9), 22-24. https://doi.org/10.6007/IJARBSS/v8i $9 / 4593$

Sumantri, U. (2019). Penggunaan Video TUto rial dalam Upaya Meningkatkan Prestasi Belajar TIK pada Siswa Kelas XII. IPS-1. Jurnal METAEDUKASI, I(2).

Surat Edaran Rektor Universitas Negeri Padang No. 1593/UN35/AK/2020 Tentang: Ke giatan Kampus dalam Rangka Kewaspa daan Pandemi Covid-19. (2020). Padang: Universitas Negeri Padang.

Thamrin, H., \& Kadarudin. (2019). Indonesia in The Industrial Revolution Era 4.0: Challenges or Threats? International Mana gement Journal.

Wheeler, S. (2012). e-Learning and Digital Learning. In N. M. Seel (Ed.), Encyclo pedia of the Sciences of Learning (pp. 1109-1111). Boston, MA: Springer US. https://doi.org/10.1007/978-1-4419-14286_431

Widya, Rifandi, R., \& Rahmi, Y. L. (2019). STEM Education to Fulfil The 21st Cen tury Demand: a literature review. Journal of Physics: Conference Series, 1317, 12208. https://doi.org/10.1088/1742-6596/ 1317/1/012208

Winarto, A. C. W. E., \& Yunianta, T. N. H. (2018). Pengembangan Mobile Learning Matematika Sebagai Suplemen Belajar SMA Kelas XI . Histogram: Jurnal Pendi dikan Matematika, 2(1). Retrieved from https://journal.stkip-andi-matappa.ac.id/ histogram/article/view/81/pdf_1 